\title{
Fácies Sedimentares e Ambientes Deposicionais Associados aos Depósitos da Formação Barreiras no Estado do Rio de Janeiro
}

\author{
Rute Maria Oliveira de Morais ${ }^{1,2}$ (rute@petrobras.com.br), Claudio Limeira Mello', \\ Fábio de Oliveira Costa ${ }^{3}$, Paula de Freitas Santos ${ }^{1}$ \\ 'Departamento de Geologia - IGEO/CCMN - UFRJ \\ Av. Brigadeiro Trompowski s/n, CEP 21941-590, Rio de Janeiro, RJ, BRA \\ ${ }^{2}$ PETROBRAS/E\&P-EXP/IABS/PS, Rio de Janeiro, RJ, BRA \\ ${ }^{3}$ Departamento de Geologia - LAGEMAR - UFF, Niterói, RJ, BRA
}

Recebido em 02 de março de 2006; aceito em 21 de junho de 2006

Palavras-chave: Formação Barreiras, fácies sedimentares, Rio de Janeiro.

\section{RESUMO}

Este trabalho apresenta um estudo faciológico dos depósitos da Formação Barreiras aflorantes no Estado do Rio de Janeiro, entre Maricá e Barra de Itabapoana. Buscou-se, além da caracterização dos processos sedimentares e ambientes deposicionais relacionados a esta sedimentação, estabelecer bases para uma possível correlação com outros depósitos terciários presentes no Estado do Rio de Janeiro, pretendendo um melhor conhecimento da evolução sedimentar cenozóica em uma região continental adjacente a importantes bacias marginais. Foram descritas três fácies de cascalho, três fácies arenosas e duas fácies lamosas, que, em associação, permitiram interpretar a atuação conjunta de processos trativos de alta energia e processos suspensivos e por fluxos gravitacionais, relacionados a um paleoambiente deposicional de rios entrelaçados com leitos arenosos, localmente dominados por cascalhos, com a participação variável de fluxos de detritos. Na região de Búzios, a ocorrência de cascalhos polimíticos sustentados pela matriz, intercalados a areias lamosas, adjacente à Falha do Pai Vitório, foi relacionada a mecanismos tectônicos sin-sedimentares associados à evolução do Graben de Barra de São João. Na maior parte da área estudada, os depósitos da Formação Barreiras encontram-se recobertos, em discordância, por sedimentos arenoargilosos, com grânulos, apresentando, na base, níveis de cascalhos formados por quartzo e fragmentos de material ferruginizado - depósitos pós-Formação Barreiras. Os depósitos da Formação Barreiras podem ser considerados como faciologicamente semelhantes aos depósitos das formações Macacu e Resende, de idade eocênica-oligocênica. Diferem, principalmente, pela intensa ferruginização observada nos sedimentos aqui estudados, não tendo sido possível a obtenção de indicadores geocronológicos que assegurem a correlação com estas unidades.

Keywords: Barreiras Formation, sedimentary facies, Rio de Janeiro.

\begin{abstract}
This paper characterizes the facies, sedimentary processes, and environments of the Barreiras Formation in the state of Rio de Janeiro between Maricá and Barra de Itabapoana. It also attempts to correlate the Barreiras deposits to well-defined Tertiary stratigraphic units in Rio de Janeiro, thereby contributing to the reconstruction of the Cenozoic sedimentary evolution of a continental area adjacent to important oceanic basins. Three gravelly facies, three sandy facies, and two muddy facies were recognized. The facies associations record high-energy traction deposits and suspension and debris-flow deposits, related to sandy to locally gravelly braided rivers, with varied occurrence of debris-flows. In Búzios, polymictic matrixsupported gravels interbedded with muddy sands occur adjacent to the Pai Vitório fault. These gravelly deposits were associated with syntectonic movements during the evolution of the Barra de São João Graben. Muddy-sandy sediments unconformably cap the Barreiras Formation. Their contact with the Barreiras Formation is generally marked by stone-lines of quartz and reworked Fe-oxide clasts. The deposits of the Barreiras Formation described here are faciologically similar to the Macacu and Resende formations (Eocene-Oligocene units). The main difference between them is the high-Fe oxidation in the Barreiras Formation deposits. Reliable geochronologic markers were not recognized in the Barreiras Formation, hence, its correlation with the Macacu and Resende formations can not be confirmed.
\end{abstract}




\section{INTRODUÇÃO}

A denominação "Barreiras" vem sendo empregada, com significado estratigráfico, desde Moraes Rêgo (1930 apud Baptista et al., 1984), para descrever depósitos arenosos e argilosos, de cores variegadas, normalmente muito ferruginizados, identificados nos baixos platôs amazônicos e nos tabuleiros da costa do norte, nordeste e leste brasileiro.

Apesar de objeto de estudo de vários autores, com a maioria dos trabalhos realizada na região nordeste, ainda não se conseguiu dar uma caracterização detalhada e amplamente aceita a estes depósitos, do ponto de vista geológico. Existem divergências importantes em termos da nomenclatura estratigráfica (Grupo ou Formação Barreiras) e sua idade tem sido admitida desde o fim do Mesozóico até o início do Quaternário, sendo normalmente aceita entre o Mioceno - Plioceno a Pleistoceno (Brito et al., 1996). Na região Sudeste, poucos foram os estudos realizados, em especial no Estado do Espírito Santo (Amador e Dias, 1978; Amador, 1982; Tamara, 1995).

Suguio e Nogueira (1999), avaliando o conhecimento estratigráfico sobre esta unidade estratigráfica, consideraram que uma melhor caracterização faciológica destes sedimentos, em conjunto com a aplicação da estratigrafia de seqüências, poderá vir a fornecer informações fundamentais para a sua reconstituição paleoambiental e paleogeográfica.

Considerando a carência de estudos estratigráficos e sedimentológicos a respeito da Formação Barreiras na região Sudeste do Brasil, particularmente no Estado do Rio de Janeiro, o trabalho aqui apresentado documenta análises faciológicas de depósitos sedimentares atribuídos a esta unidade entre Maricá e Barra de Itabapoana. Através da caracterização faciológica realizada, buscou-se, além da interpretação paleoambiental desses depósitos, contribuir para o conhecimento do quadro estratigráfico do Cenozóico do Estado do Rio de Janeiro, onde seja possível a correlação da Formação Barreiras com unidades cenozóicas melhor estabelecidas (formações Macacu e Resende), fundamental para um maior entendimento acerca da evolução sedimentar cenozóica em região continental adjacente a importantes bacias marginais.

\section{GEOLOGIA DA ÁREA DE ESTUDO}

Segundo o mais recente mapa geológico do Estado do Rio de Janeiro (Silva e Cunha, 2001), a maior expressão dos depósitos da Formação Barreiras no estado ocorre na região da planície costeira do rio Paraíba do Sul (Figura 1), constituindo o limite oeste desta planície, particularmente a norte da foz deste rio. Nesta região, os depósitos da Formação Barreiras atingem o litoral, onde, por ação direta das ondas, são esculpidas falésias. Esta unidade também ocorre na região de Quissamã e, mais restritamente, próximo às cidades de Búzios e Macaé.
Nesta área, as rochas pré-cambrianas estão relacionadas aos domínios tectono-magmáticos Região dos Lagos (Complexo Região dos Lagos - ortognaisses paleoproterozóicos; e Complexo Búzios - rochas supracrustais meso a neoproterozóicas) e Serra do Mar (Complexo Paraíba do Sul - supracrustais metamorfizadas na fácies anfibolito, meso a neoproterozóicas; granitóides neoproterozóicos do arco magmático Rio de Janeiro) - Silva e Cunha (2001). Além dos depósitos da Formação Barreiras, as unidades cenozóicas relacionam-se às bacias continentais terciárias da região oriental do Estado do Rio de Janeiro, destacando-se os depósitos da Formação Macacu, de idade eocênica-oligocênica (Ferrari, 2001), o Graben de Barra de São João e as formações superficiais quaternárias.

\section{MÉTODOS E TÉCNICAS}

Inicialmente, foram realizadas atividades de campo para a seleção de afloramentos mais representativos nas áreas de ocorrência da Formação Barreiras no Estado do Rio de Janeiro. Utilizou-se como critério de seleção a presença de seções bem expostas, como as localizadas em cortes de rodovias ou exposições naturais, que favorecessem a observação dos depósitos em questão.

$\mathrm{Na}$ descrição dos afloramentos selecionados, contouse com o auxílio de fotomosaicos previamente interpretados.

A caracterização faciológica detalhada dos depósitos sedimentares foi feita a partir da descrição da granulometria, cor, composição mineralógica e, principalmente, estruturas sedimentares e geometria das camadas. A cor dos sedimentos foi considerada de maneira restrita, devido ao elevado grau de ferruginização em que estes depósitos se encontram. Medidas de paleocorrentes foram obtidas, quando possível, a partir da análise de estratificações cruzadas em sedimentos arenosos e da orientação de seixos nos depósitos de cascalhos.

Foram coletadas amostras representativas das fácies arenosas e lamosas, para a realização de análises granulométricas, com o objetivo de contribuir para a caracterização faciológica pretendida. Estas análises granulométricas, realizadas no Laboratório de Sedimentologia do Departamento de Geologia (IGEO/UFRJ), seguiram os procedimentos descritos por Folk (1980).

Com a finalidade de investigar a origem da fração argilosa nas amostras arenosas, foram elaboradas lâminas petrográficas de três amostras, após impregnação com Araldite.

\section{ANÁLISES FACIOLÓGICAS}

\section{Fácies sedimentares}

Foram reconhecidas três fácies de cascalhos (Cch, $\mathrm{Ccp}$ e Cmm), três fácies arenosas (Aca, Ah e Am) e duas fácies lamosas (La1 e La2) - Tabela 1. 


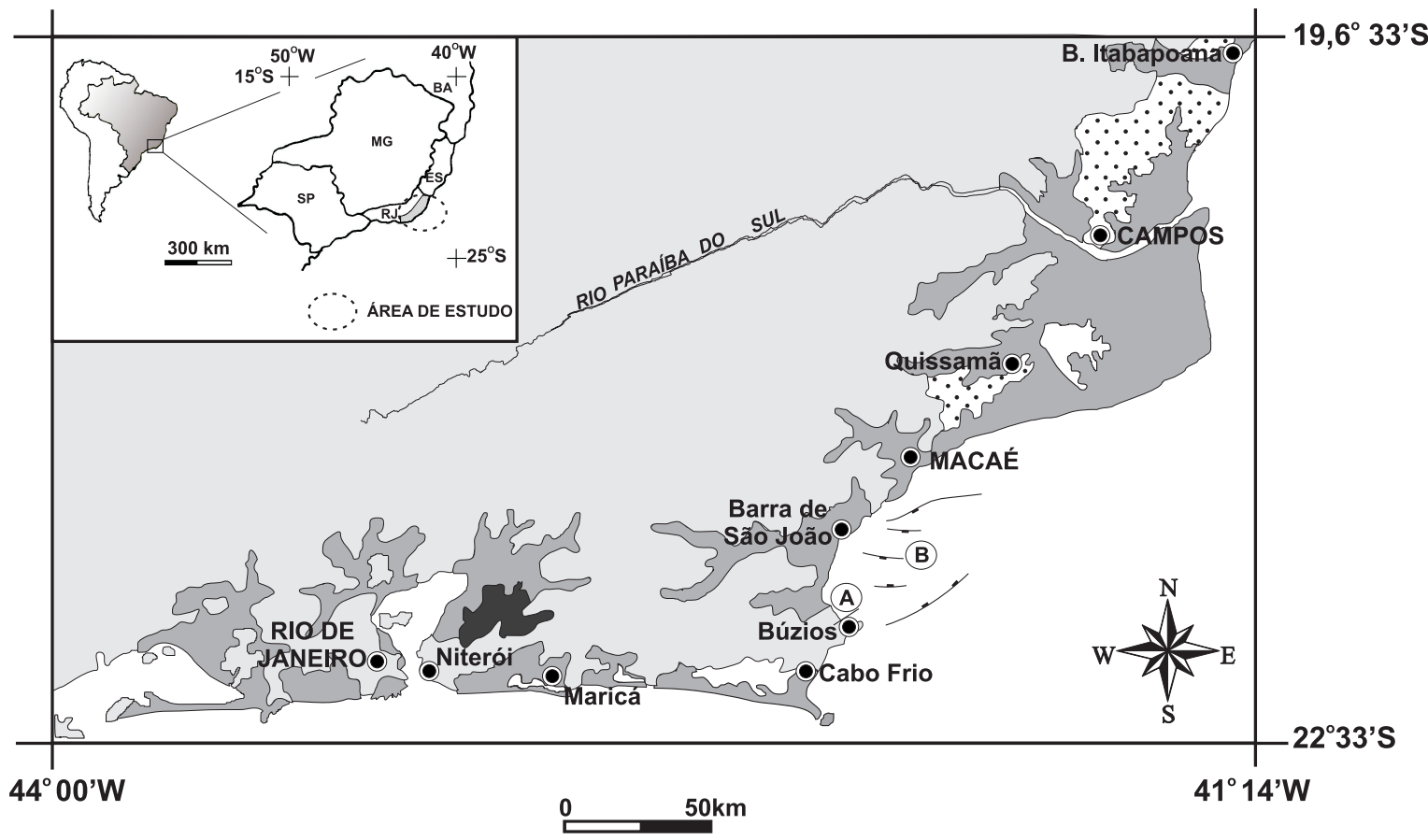

\section{LEGENDA}

Depósitos quaternários

Formação Barreiras (NEÓGENO ?)

Formação Macacu (PALEÓGENO ?)
Embasamento pré-cambriano

(A) Falha do Pai Vitório

B Graben de Barra de São João

Figura 1. Mapa geológico abrangendo a área estudada, destacando as unidades cenozóicas. Modificado de Schobbenhaus et al. (1984).

Tabela 1. Códigos, características e interpretação das fácies sedimentares estudadas.

\begin{tabular}{|c|c|c|}
\hline Código & Descrição & Interpretação \\
\hline Cch & $\begin{array}{c}\text { Cascalhos sustentados pelos clastos, com } \\
\text { estratificação horizontal pouco definida e clastos } \\
\text { comumente imbricados }\end{array}$ & Barras longitudinais; depósitos residuais \\
\hline Ccp & $\begin{array}{c}\text { Cascalhos sustentados pelos clastos, com } \\
\text { estratificação cruzada }\end{array}$ & Migração de barras transversais de cascalhos \\
\hline $\mathrm{Cmm}$ & Cascalhos sustentados pela matriz, maciços & Fluxo de detritos de alta energia \\
\hline Aca & $\begin{array}{l}\text { Areias com estratificação cruzada acanalada de } \\
\text { baixo ângulo }\end{array}$ & Migração de megaondulações de crista sinuosa \\
\hline $\mathrm{Ah}$ & Areias com estratificação horizontal & Migração de formas de leito plano \\
\hline Am & Areias maciças ou sem estrutura aparente & $\begin{array}{l}\text { Depósitos de fluxos gravitacionais de } \\
\text { sedimentos; modificações pós-deposicionais; } \\
\text { intensa decantação de areia em suspensão }\end{array}$ \\
\hline La1 & Lamitos argilosos & $\begin{array}{c}\text { Decantação de finos ou fluxos gravitacionais de } \\
\text { sedimentos }\end{array}$ \\
\hline La2 & Lamitos arenosos & Fluxos gravitacionais de sedimentos \\
\hline
\end{tabular}




\section{Fácies de cascalho}

\section{Fácies Cch}

Corresponde a cascalhos sustentados pelos clastos, com estratificação horizontal pouco definida e clastos comumente imbricados (Figura 2a). Ocorrem em camadas com geometria lenticular a lenticular extensa, apresentando seixos e blocos arredondados a subarredondados, com cerca de até 10 a $15 \mathrm{~cm}$ de eixo maior. Os clastos são predominantemente quartzosos, ocorrendo em menor quantidade clastos de feldspato e de litoclastos alterados.

Descritivamente, esta fácies pode ser relacionada à fácies Gh de Miall (1996). Segundo Boggs (1992), depósitos com estas características podem ser interpretados como de fluxos em lençol (sheetflood), resultantes de processos trativos subaquosos e unidirecionais, preenchendo o fundo de canais entrelaçados ou associados a fluxos pouco canalizados. Segundo o mesmo autor, também podem ser interpretados como produto da migração de barras longitudinais em fluxos canalizados (streamflow).

\section{Fácies Ccp}

Representada por cascalhos sustentados pelos clastos, com estratificação cruzada (Figura 2b). Estes depósitos caracterizam-se por clastos predominantemente quartzosos, arredondados a subarredondados, com tamanho médio variando de 10 a $15 \mathrm{~cm}$ de eixo maior.

Esta fácies relaciona-se à fácies Gp de Miall (1996). Seu processo formador está associado à movimentação de cascalhos no leito de cursos fluviais, sob a ação de fluxos trativos unidirecionais, por acreção vertical combinada ao crescimento para jusante de barras fluviais transversais.

\section{Fácies $\mathrm{Cmm}$}

Esta fácies corresponde a cascalhos maciços, polimíticos, sustentados pela matriz (Figura 2c). O tamanho de seus clastos varia desde 10 a $20 \mathrm{~cm}$ (em média) até $1 \mathrm{~m}$ de eixo maior; suas camadas podem apresentar uma geometria subtabular a lenticular. Estes depósitos apresentam matriz de composição areno-argilosa e feldspática.

Pode ser relacionada à fácies Gmm de Miall (1996). Segundo este autor, os depósitos associados à fácies $\mathrm{Gmm}$ são formados por processos de fluxos de detritos de alta energia, podendo ocupar topografias pré-existentes como, por exemplo, canais. Segundo Boggs (1992), os depósitos de cascalho formados por processos de fluxos de detritos podem ser intercalados a depósitos provenientes de fluxos em lençóis ou fluxos canalizados. Nos processos de fluxos gravitacionais, a matriz tem força coesiva e flutuabilidade suficientes para suportar os cascalhos e grandes blocos (Boggs, 1992).

\section{Fácies arenosas}

\section{Fácies Aca}

Corresponde a areias grossas a muito grossas, pouco selecionadas, quartzosas a feldspáticas, com estratificações cruzadas acanaladas de ângulo baixo (Figura 3a). Pode apresentar concentrações de cascalho na base das camadas e, por vezes, observa-se a presença de intraclastos de argila. Apresenta-se, geralmente, bastante ferruginizada, com cores predominantemente avermelhadas.

Este tipo de fácies desenvolve-se através de processos trativos unidirecionais, por migração de megaondulações de crista sinuosa, em regime de fluxo inferior. Corresponde à fácies St de Miall (1996).

\section{Fácies Ah}

Representada por areias grossas a muito grossas, quartzosas a feldspáticas, com estratificação horizontal. Por vezes, nota-se que a estratificação é determinada por alinhamento pouco definido de seixos. Apresenta cores avermelhadas, relacionadas à intensa ferruginização. Intraclastos de argila podem estar associados a esta fácies.

Em alguns depósitos, observa-se crosta de ferruginização com padrão horizontalizado, acreditando-se que este padrão pode estar sendo controlado pela estratificação primária.

Forma-se por processos trativos unidirecionais, pela migração de formas de leito plano. Esta fácies corresponde à fácies Sh de Miall (1996).

\section{Fácies Am}

Esta fácies corresponde a areias médias a grossas, maciças ou sem estrutura aparente (Figura 3b), com grãos angulosos a subangulosos, mal selecionados, quartzosos e feldspáticos. Geralmente possui matriz caulínica, apresentando, em algumas situações, seixos de quartzo, feldspato e, por vezes, litoclastos dispersos. Estes seixos freqüentemente ocorrem localizados em camadas delgadas ou na base das camadas. A cor é freqüentemente cinza esbranquiçada a arroxeada, devido à ferruginização.

Pode ser correlacionada à fácies Sm de Miall (1996). Experimentos realizados por Arnott e Hand (1989 apud Boggs, 1992) demonstraram que, em condições de leito plano, de regime de fluxo superior, devido à intensa decantação de areia em suspensão (típica de corrente de turbidez), a formação de laminações é suprimida. No entanto, a estrutura ori- 

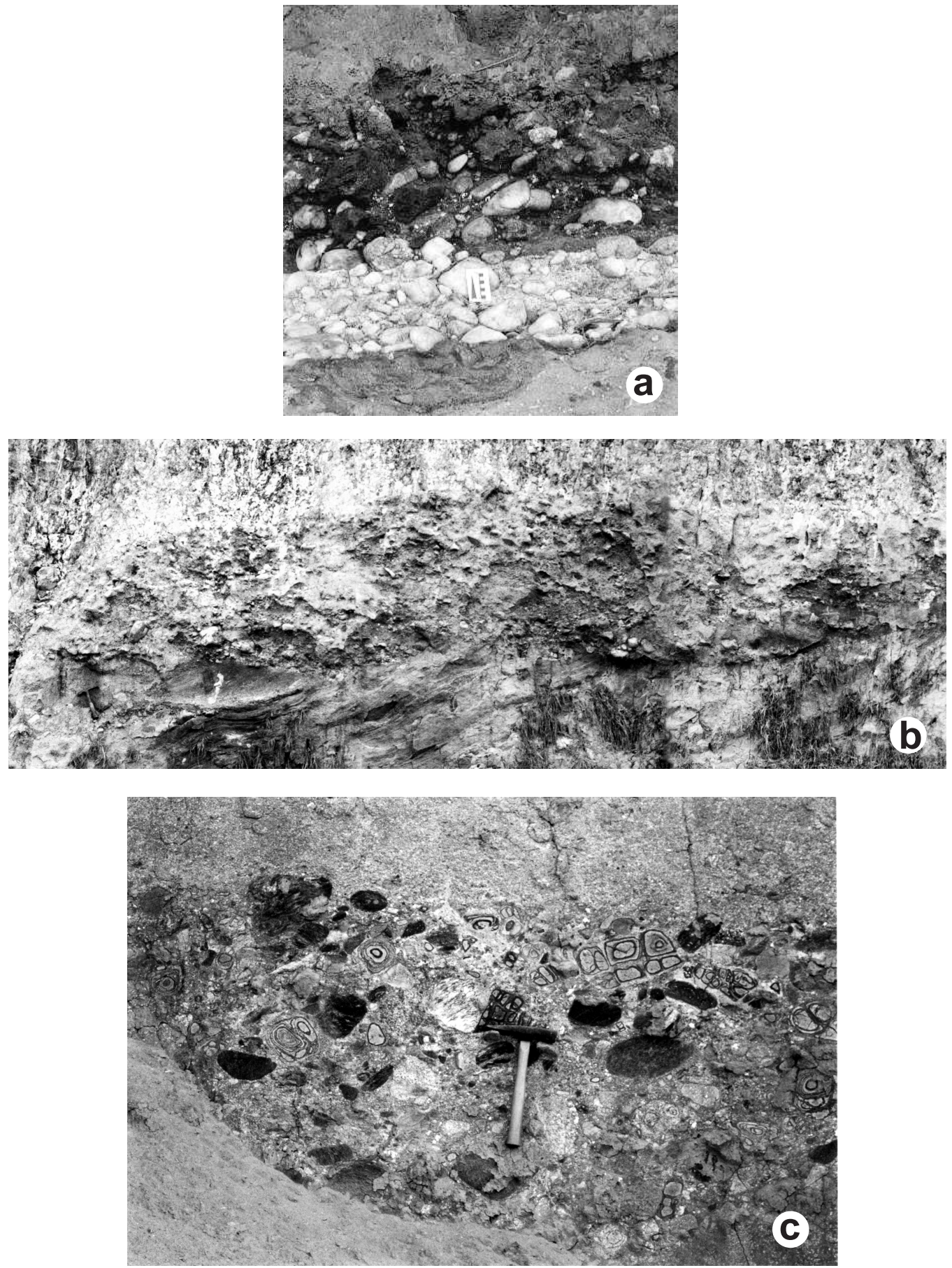

Figura 2. a. Fácies Cch, destacando-se o padrão de estratificações horizontais e clastos imbricados - Praia Rasa, região de Búzios. b. Fácies Ccp em inconformidade sobre o embasamento précambriano alterado - Trevo da Via Lagos, São Pedro D'Aldeia. c. Fácies Cmm - falésias da Praia Rasa, região de Búzios. 

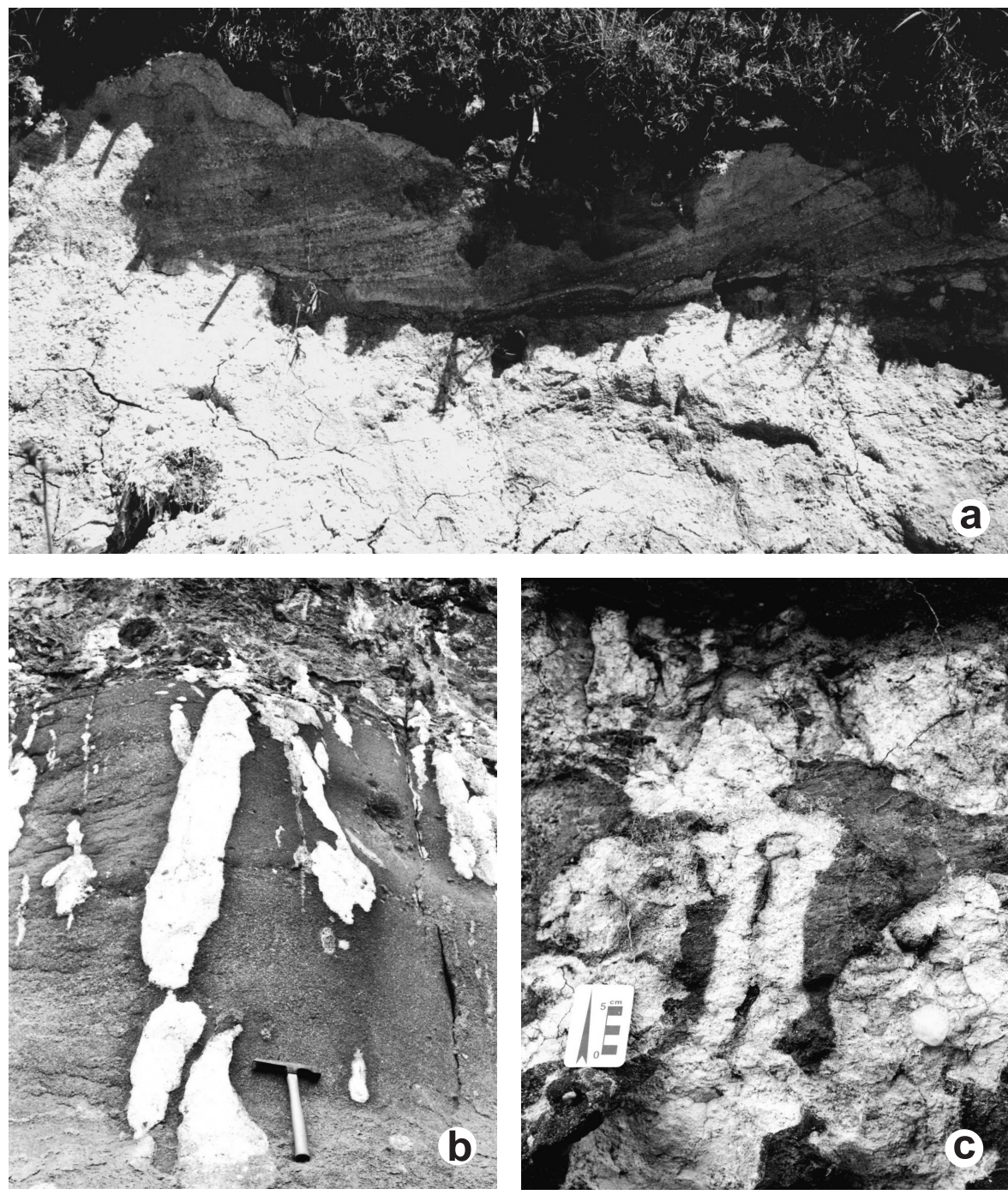

Figura 3. a. Fácies Aca - afloramento na entrada da cidade de Macaé. b. Fácies Am - falésias da Praia Rasa, região de Búzios. c. Aspecto geral das fácies lamosas, em afloramento na Praia Rasa, região de Búzios.

ginal nestas areias pode ter sido destruída ou mascarada pela ferruginização, que é uma característica comum dos depósitos em estudo. Quando apresentam seixos dispersos e maior abundância de matriz, depósitos desta fácies podem estar associados a fluxos gravitacionais de sedimentos.

\section{Fácies lamosas}

\section{Fácies Lal}

Compõe-se de lamitos argilosos, maciços, de cores variando de branca acinzentada a arroxeada, devido à ferruginização (Figura 3c). Ocorrem grânulos e pequenos seixos de quartzo dispersos em meio à matriz caulínica.
Por apresentarem características de sedimentos finos, podendo apresentar grãos dispersos, esta fácies parece indicar depósitos relacionados a processos suspensivos ou a processos de fluxos gravitacionais.

\section{Fácies La2}

Compõe-se de lamitos arenosos, maciços, com grânulos e seixos de quartzo e feldspato alterado dispersos na matriz caulínica (Figura 3c). Apresenta, geralmente, forte mosqueamento, por ferruginização, e as mesmas cores dos sedimentos da fácies La1.

Os sedimentos da fácies La2 foram relacionados à atuação de processos de fluxos gravitacionais. 


\section{Análises petrográficas}

Nos diagramas de caracterização granulométrica geral dos sedimentos arenosos e lamosos (Figura 4), é visível uma tendência de as amostras se concentrarem nos campos das argilas arenosas e areias argilosas.

$\mathrm{O}$ registro de porcentagens relativamente elevadas de argila em fácies reconhecidamente interpretadas como arenosas, inclusive apresentando estruturas sedimentares de origem trativa (fácies Ah e Aca), é um forte indício de que estes depósitos sofreram alteração de seus grãos (caolinização de grãos de feldspatos) ou a iluviação de argilas autigênicas.

A descrição de lâminas petrográficas de sedimentos da fácies Am mostra um percentual significativo de feldspatos (principalmente microclina), permitindo classificar estes sedimentos como areias arcozianas a subarcozianas. $\mathrm{O}$ arcabouço é composto de grãos de areia fina a grossa, angulosos a subangulosos, com presença de matriz relativamente abundante, com graus variados de ferruginização.

Pôde-se observar que a matriz é predominantemente de origem pós-deposicional, provindo da alteração dos grãos de feldspatos, que se encontram caulinizados (Figuras $5 \mathrm{a} \mathrm{e}$ 5 b). Ocorre biotita em pequena quantidade, apresentando feições de alteração (Figura 5c), o que indica que o aspecto ferruginizado da matriz é, em parte, proveniente do ferro liberado por este mineral.

\section{INTERPRETAÇÃO PALEOAMBIENTAL}

Os depósitos da Formação Barreiras no Estado do Rio de Janeiro exibem associações faciológicas características de ambiente fluvial entrelaçado, com algumas variações dentro do modelo, de acordo com a região estudada.

A área de estudo foi dividida em três setores, buscandose agrupar seções estratigráficas que apresentassem características semelhantes: Norte Fluminense, Búzios e Região dos Lagos.

$\mathrm{Na}$ maior parte da área estudada, os depósitos da Formação Barreiras encontram-se recobertos, em discordância, por sedimentos areno-argilosos, com grânulos, castanho-amarelados, delimitados na base por nível de cascalhos de quartzo e fragmentos de material ferruginizado depósitos pós-Formação Barreiras.

\section{Região Norte Fluminense}

Os depósitos neste setor, que abrange as ocorrências na região de Quissamã e na região da planície costeira do rio Paraíba do Sul, são compostos, predominantemente, por sedimentos arenosos (fácies Aca e Am) intercalados com sedimentos lamosos (fácies La1 e La2), com pouca participação de níveis de cascalho (fácies Cch) - Figura 6. Em geral, as camadas apresentam-se com geometria de lentes extensas a subtabulares. A cor dos depósitos é branca-acinzentada, com forte mosqueamento vermelhoarroxeado, com a presença, inclusive, de níveis limoníticos delimitando camadas e crostas ferruginosas bem desenvolvidas.

Os depósitos descritos neste setor são associados a uma sedimentação por processos trativos (fácies Cch, Aca e Am), com pequena participação dos processos suspensivos e de fluxos gravitacionais (fácies La1 e La2). São interpretados como de ambiente fluvial entrelaçado distal.

\section{Região de Búzios}

Neste setor, destacam-se depósitos de cascalhos muito grossos, polimíticos, sustentados pela matriz (fácies $\mathrm{Cmm}$ ), maciços, podendo apresentar gradação normal. O tamanho dos clastos do arcabouço varia de seixo a matacão, podendo atingir cerca de $1 \mathrm{~m}$ de eixo maior (Figura 7). Estes depósitos de cascalho dispõem-se em camadas de geometria lenticular a lenticular extensa e ocorrem intercalados a camadas de areias muito grossas, com matriz argilosa, avermelhadas, maciças (fácies Am) e camadas de fácies lamosas (La1 e La2), de cor brancaacinzentada, porém intensamente ferruginizadas. Também ocorrem intercalados a camadas de geometria lenticular a subtabular das fácies Cch e Aca.

Os depósitos na região de Búzios indicam a atuação importante de fluxos gravitacionais de sedimentos (fácies Cmm, Am, La1 e La2), com a participação também de processos trativos de alta energia (fácies Cch, Aca e Am). Podem ser relacionados a leques aluviais do tipo dominado por fluxos gravitacionais, associados a um ambiente fluvial entrelaçado dominado por cascalhos.

\section{Região dos Lagos}

Neste setor, localizado entre Maricá e Búzios, ocorre o predomínio de fácies de cascalhos (fácies Cch e Ccp) intercaladas com sedimentos arenosos (fácies Am e Aca) - Figura 8 e lamosos (fácies La1 e La2). Estes depósitos apresentam geometria lenticular a lenticular extensa, e cor geralmente branco-acinzentada, podendo variar em função do mosqueamento.

A intercalação de fácies de cascalho, arenosas e lamosas indica ação conjunta de processos trativos de alta energia (fácies Cch, Ccp, Am e Aca) e de fluxos gravitacionais (La1 e La2), levando à interpretação de um modelo deposicional de ambiente fluvial entrelaçado dominado por cascalhos, com elevada contribuição de fluxos gravitacionais. 


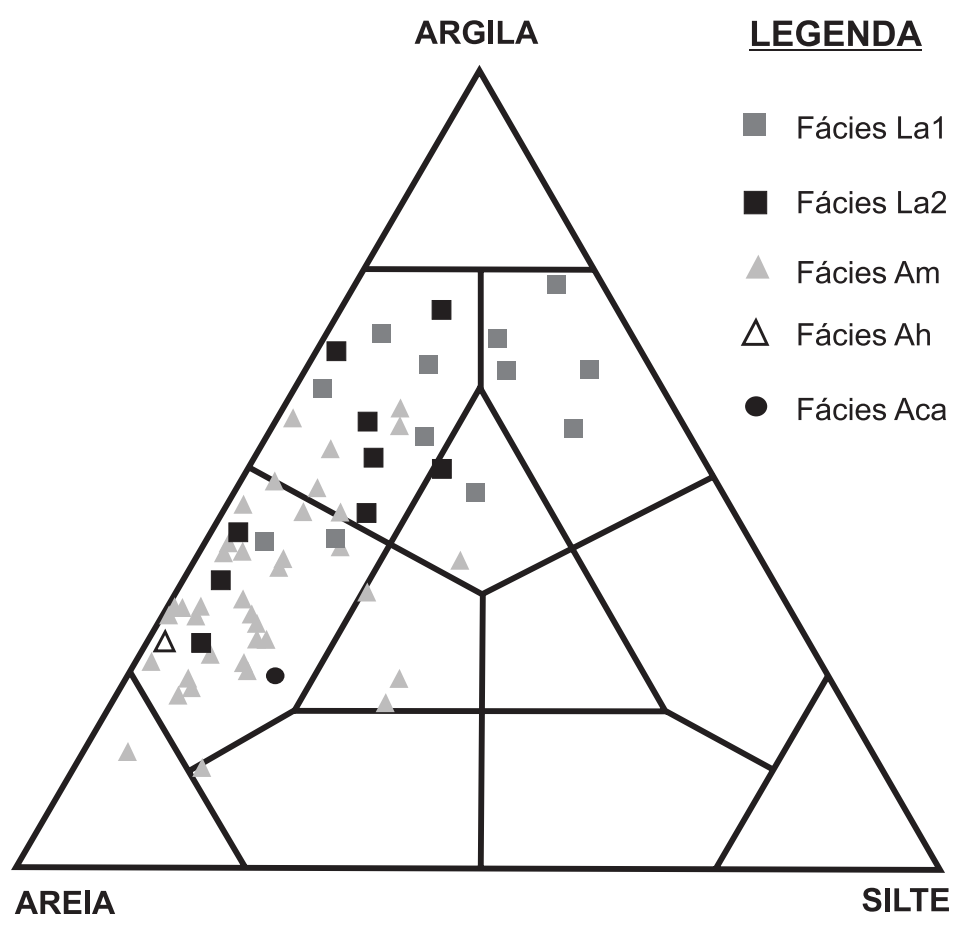

Figura 4. Diagrama triangular de caracterização granulométrica das fácies sedimentares arenosas e lamosas identificadas na área estudada.
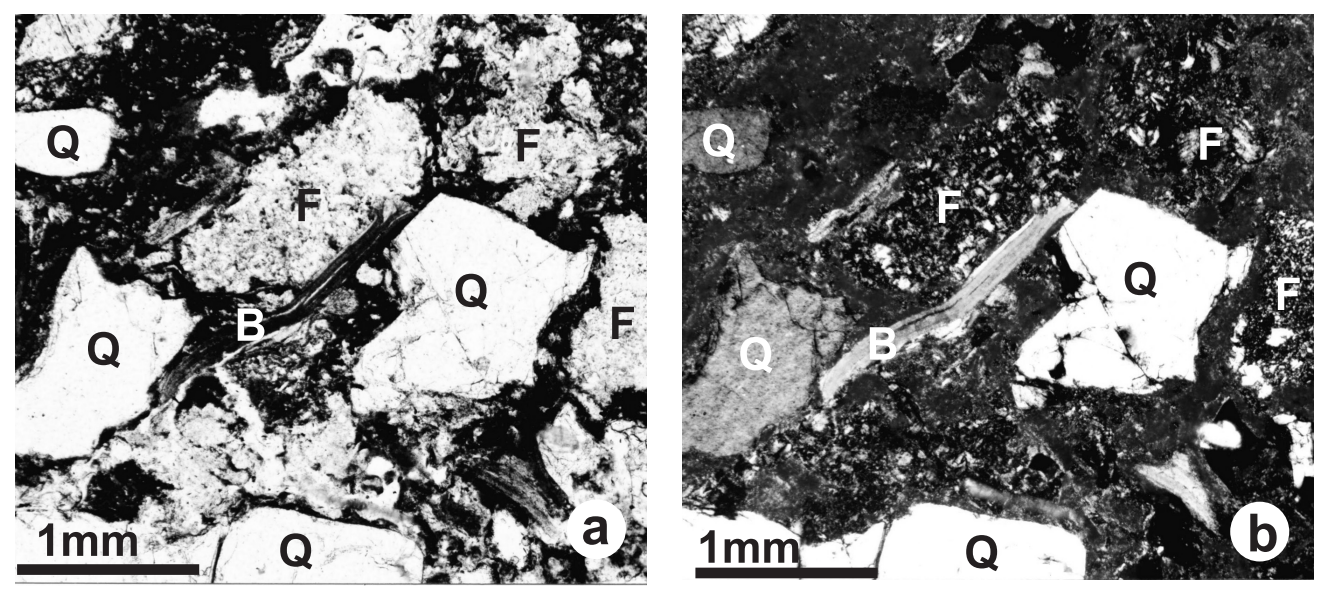

Figura 5. Fotomicrografias de sedimentos da fácies Am. a. Aspecto dos grãos de quartzo (Q), feldspato (F) e biotita (B) com nicóis paralelos. b. Aspecto dos grãos de quartzo, feldspato e biotita com nicóis cruzados, ressaltando-se o grau de alteração dos grãos de feldspato. c. Feições de alteração em grão de biotita.

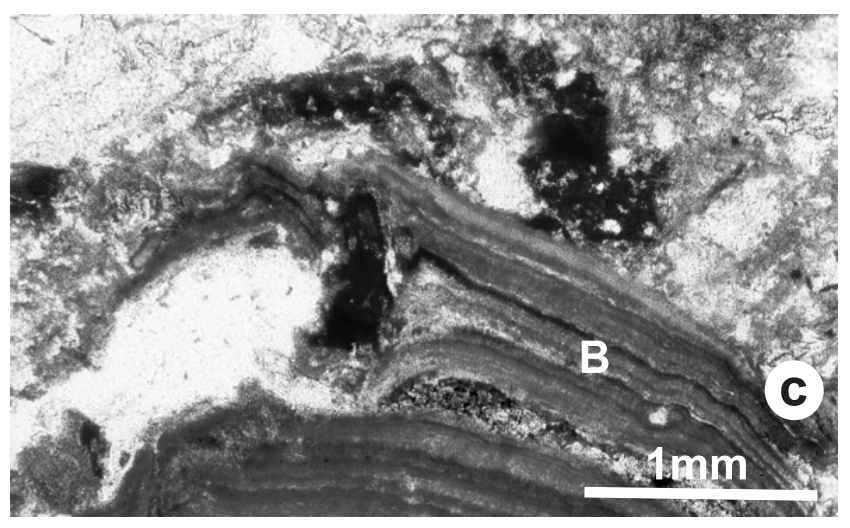




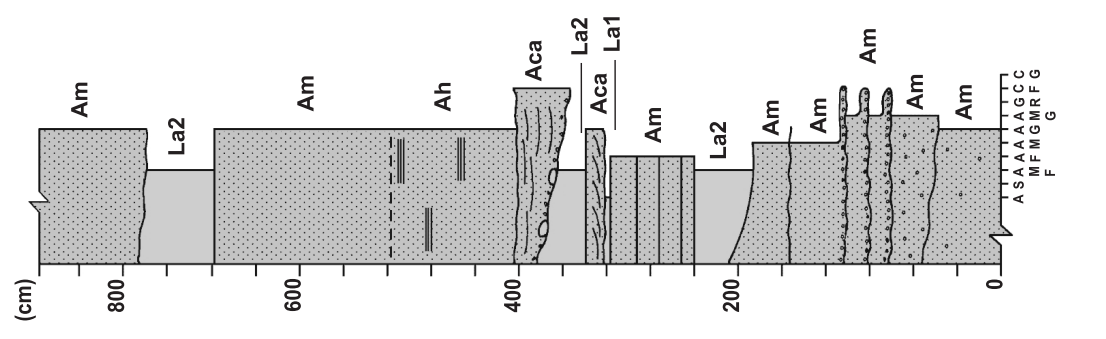

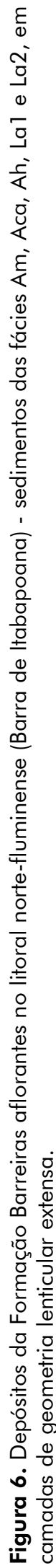

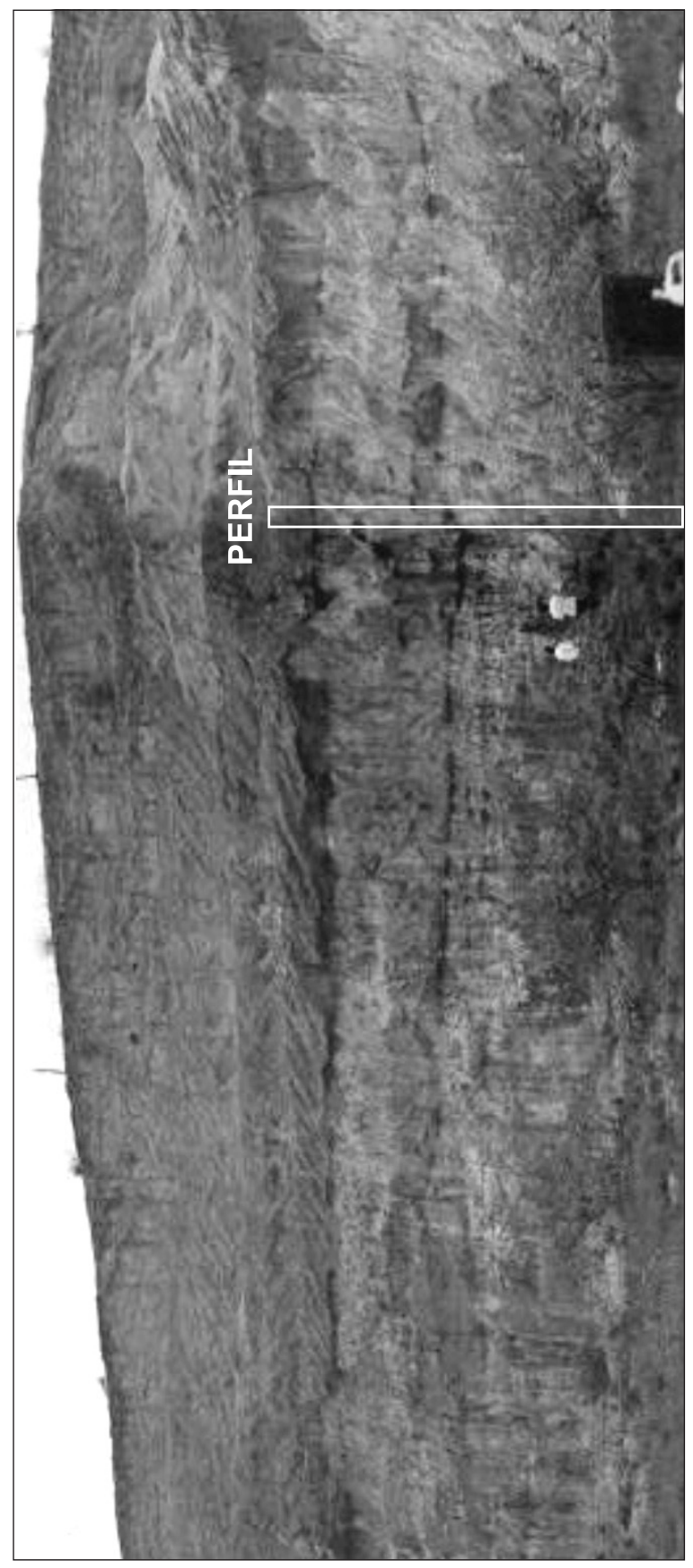




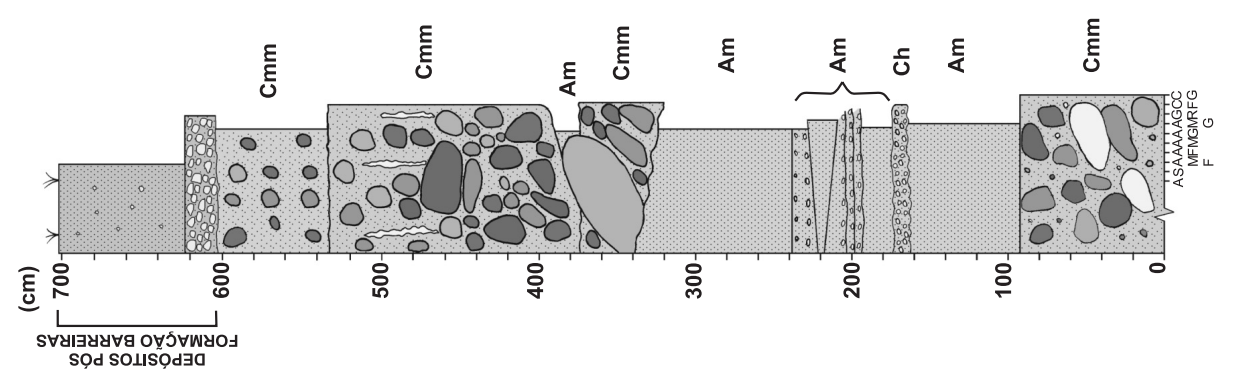

$\frac{\varepsilon}{0} \frac{0}{5}$

运这

.

흥 응

은 융

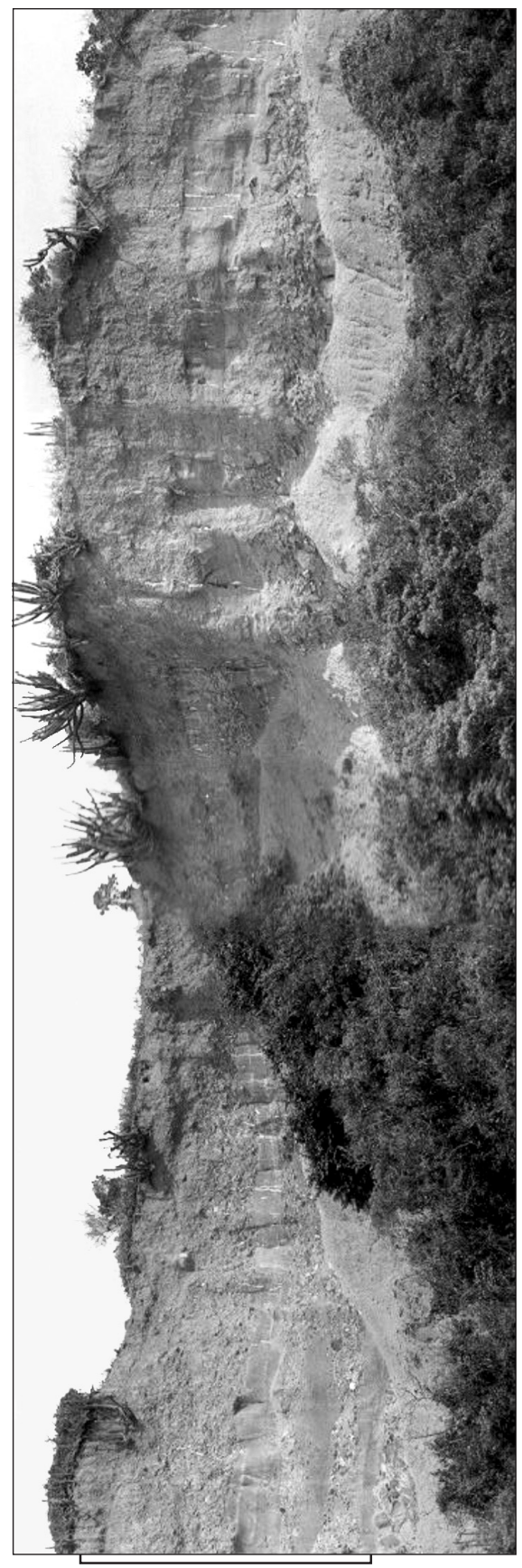

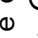

$\frac{1}{\varepsilon} \cdot \frac{0}{\mathrm{~s}}$

U⿺辶寸

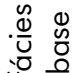

등 응

足

둔 웅

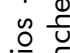

忿

$\frac{1}{0}$

은

ฮํㅡㅁ

으으

¿

읗

인

응 을

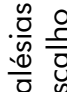

눙

읃 음

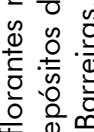

is 0

옹 \&

क्षे है

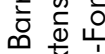

웡.

늠 흔

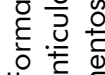

过.

응. 흔

号

○.

๑ั

$\wedge$ 잉

옥 응 흠

ロ யᄄ レ - 


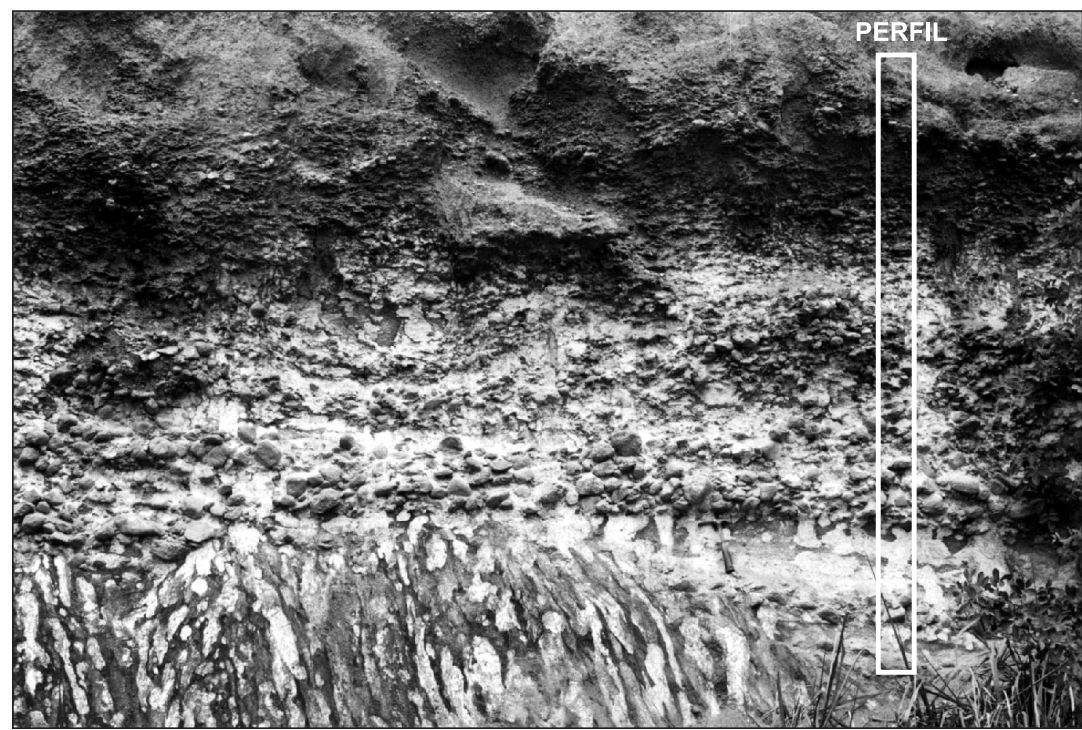

Figura 8. Depósitos da Formação Barreiras aflorantes na região de Maricá camadas de cascalhos da fácies Cch intercaladas a camadas arenosas da fácies Am. Observa-se, no topo da seção, sedimentos pós-Formação Barreiras.

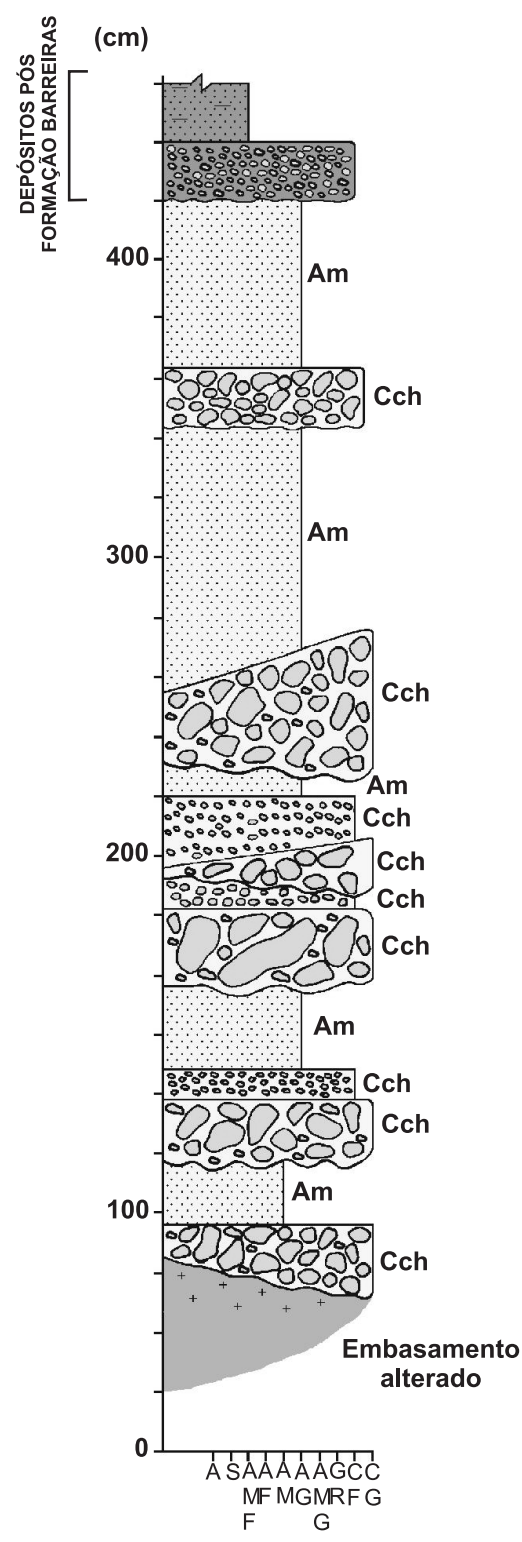

\section{CONCLUSÕES}

A caracterização faciológica dos depósitos da Formação Barreiras aflorantes no Estado do Rio de Janeiro permitiu relacioná-los a um ambiente fluvial entrelaçado, com variações dentro deste modelo deposicional. Os depósitos estudados na região Norte Fluminense exibem associações de fácies de ambiente fluvial entrelaçado arenoso distal. Os depósitos descritos nas regiões de Búzios e dos Lagos indicam deposição em um ambiente fluvial entrelaçado dominado por cascalhos, com participação importante de fluxos gravitacionais, documentando uma situação mais proximal.

Na região de Búzios, a associação de cascalhos polimíticos sustentados pela matriz (fácies $\mathrm{Cmm}$ ) e areias lamosas maciças (fácies Am), adjacente à falha do Pai Vitório, sugere a atuação de mecanismos tectônicos sin-sedimentares, provavelmente associados à evolução do Graben de Barra de São João, de idade eocênica (Mohriak e Barros, 1990).

Considerando-se as características faciológicas e paleoambientais, os depósitos estudados assemelham-se aos depósitos das formações Resende e Macacu, de idade eocênica-oligocênica, estudados por Ramos (2003) e Ferrari (2001), respectivamente. Diferem, principalmente, pela intensa ferruginização observada nos sedimentos aqui estudados.

A falta de indicadores geocronológicos seguros não permite estabelecer a idade dos depósitos da Formação Barreiras na área estudada, nem assegurar a sua correlação com as unidades estratigráficas mencionadas. Porém, os 
elementos disponíveis para a correlação entre os depósitos aqui estudados e as unidades estratigráficas cenozóicas melhor estabelecidas no Estado do Rio de Janeiro levam a considerar a possibilidade de os sedimentos relacionados à Formação Barreiras no Rio de Janeiro poderem ter se desenvolvido dentro do contexto do tectonismo cenozóico que levou à formação do sistema de pequenas bacias sedimentares continentais tafrogênicas que constituem o Rift Continental do Sudeste do Brasil (RCSB, EocenoOligoceno, Riccomini, 1989).

\section{AGRADECIMENTOS}

Agradecemos à FAPERJ (processo n ${ }^{\circ}$ E-26/170.402/2000) e ao Projeto ACOST_RIO (FINEP/PADCT - convênio 88-98-0760-00, coordenado pelo Prof. Dr. Gerson Cardoso da Silva Jr., Depto. Geologia/IGEO-UFRJ) pelos recursos financeiros utilizados para a realização dos trabalhos de campo. Ao Programa de Pós-Graduação em Geologia/IGEOUFRJ, pela concessão da verba do PROAP/CAPES para a realização das atividades de laboratório. Ao técnico do Laboratório de Sedimentologia (Depto. Geologia - IGEO/UFRJ), Luiz Antonio Sampaio Ferro (in memoriam), agradecemos por sua colaboração nas análises laboratoriais. Agradecemos aos revisores, Kenitiro Suguio e Francisco Hilário Rego Bezerra, pelas correções e sugestões feitas a este trabalho. A primeira autora agradece ao CNPq pela concessão de bolsa de mestrado.

\section{REFERÊNCIAS BIBLIOGRÁFICAS}

AMADOR, E. S. Depósitos relacionados à Formação inferior do Grupo Barreiras no Estado do Espírito Santo. In: CONGRESSO BRASILEIRODE GEOLOGIA, 32., 1982. Salvador. Anais... Salvador: SBG, 1982. v. 4, p. 1451-1460.

AMADOR, E. S.; DIAS, G. T. M. Considerações preliminares sobre depósitos do Terciário Superior do norte do Espírito Santo. Anais da Academia Brasileira de Ciências, v. 50, n. 1, p. 121, 1978.

BOGGS, S. Petrology of sedimentary rocks. New York: Macmillan Publishing Company, 1992. 707 p.

BRITO, I. M.; MELLO, C. L.; MADEIRA, C. V. Avaliação do significado estratigráfico do termo Barreiras. Anais da Academia Brasileira de Ciências, v. 69, n. 1, p. 136-137, 1996.

BAPTISTA, M. B.; BRAUN, O.P.G; CAMPOS, D. A.; PRICE, L. I.; RAMALHO, R.; SANTOS, N. G. Léxico estratigráfico brasileiro. Brasília: Departamento Nacional da Produção Mineral, 1984.541 p.
FERRARI, A. L. Evolução Tectônica do Graben da Guanabara. 2001. 412 f. Tese (Doutorado) - Instituto de Geociências, Universidade de São Paulo, São Paulo, 2001.

FOLK, R. L. Petrology of sedimentary rocks. Austin: Univ. Texas, $1980.170 \mathrm{p}$.

MIALL, A. D. The Geology of Fluvial Deposits: sedimentary facies, basin analysis, and petroleum geology. New York: Springer, $1996.582 \mathrm{p}$.

MOHRIAK, W. U. ; BARROS, A. Z. N. Novas evidências de tectonismo cenozóico na região sudeste do Brasil: o Graben de Barra de São João na plataforma de Cabo Frio, RJ. Revista Brasileira de Geociências, v. 20, n. 1-4, p. 187-196, 1990.

RAMOS, R. R. C. Sistemas Aluviais Terciários da Bacia de Resende, Estado do Rio de Janeiro, Brasil: análise de fácies e revisão estratigráfica. 2003. $221 \mathrm{f}$. Tese (Doutorado) Depto. de Geologia, Instituto de Geociências, Universidade Federal do Rio de Janeiro, Rio de Janeiro, 2003.

RICCOMINI, C. O Rift Continental do Sudeste do Brasil. 1989. 256 f. Tese (Doutorado) - Instituto de Geociências, Universidade de São Paulo, São Paulo, 1989.

SCHOBBENHAUS, C. ; CAMPOS, D. A.; DERZE, G. R.; ASMUS, H. E. Geologia do Brasil - texto explicativo do mapa geológico do Brasil e da área oceânica adjacente, incluindo depósitos minerais, escala 1:2.500.000. Brasília: Departamento Nacional de Produção Mineral, 1984. 501 p.

SILVA, L C.; CUNHA, H. C. S. Geologia do Estado do Rio de Janeiro: texto explicativo do mapa geológico do Estado do Rio de Janeiro, escala 1:400.000. Brasília: CPRM, 2001. (1 CD-ROM).

SUGUIO, K. ; NOGUEIRA, A. C. R. Revisão crítica dos conhecimentos geológicos sobre a Formação (ou Grupo?) Barreiras do Neógeno e o seu possível significado como testemunho de alguns eventos geológicos mundiais. Geociências, São Paulo, v. 18, n. 2, p. 461-479, 1999.

TAMARA, G. Contribuição ao Estudo do Grupo Barreiras na Região Metropolitana de Vitória (ES). 1995. $73 \mathrm{f}$. Dissertação (Mestrado) - Depto. Geologia, Instituto de Geociências, Universidade Federal do Rio de Janeiro, Rio de Janeiro, 1975. 